\title{
Grupo sanguíneo P1 y su relación con cicatriz renal en pacientes con infección urinaria
}

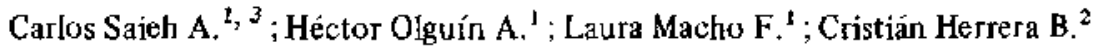 \\ Renal scars and $P$ blood subgroup
}

\begin{abstract}
Possible relationships betwoen renal scars and $P$ biood group have been ecently emphasized. Urinary tract infections, an important factor in the production of renal scar, are mainly caused by specific types of $\boldsymbol{E}$. coli, wnich has the ability to adhere through fimbriae, to receptors of the urinary tract epithejium that are structurally related to antigens detected in people with blood group P1. We looked for P 1 sub-group in 30 children with vesicoureteral reflux and rena! scar and 30 patients with equivalent degrees of reflux but without evidence of renat scar. Sex and age were unmatched. The frequency of $P 1$ blood subgroup was similar in both kinds of patients $456.7 \%$ vs. 66.7 , n.s.) so we could not demonstrate that P1 sub-group can be a useful indirect risk marker for rena: scar formation. (Key words: Blood groups, P1 blood sub-group, renal scars, risk factors, vesicoureteral reflux.)
\end{abstract}

La infección urinaria (ITU) es un problema frccuente en pediatria, especialmente en los primeros anos de vida. Su diagnóstico, tratamiento y posteriores controles han dejado de ser un problema en la actualidad, pero persiste un grupo de enfermos en que esta infección compromete al riñón, provocando un daño irreversible $^{1-4}$. Para que esta última condición sea posible. tienen que estar presentes factores del huésped, especialmente anatómicos, tales como reflujo vesicoureteral, estenosis, obstrucciones, etc.. y factores dependientes del agente causal de la ITU, como los antígenos O o K de E. coli,

1. Hospital Luis Calvo Mackenna.

2. Hospital Roberto del Río.

3. Clínica Las Condes. producción de hemolisinas y la capacidad de adherencia de los gérmenes a las células del epitelio urinario.

La mayoria de las ITU son causadas por $E$. coli, agente dotado de fimbrias, que tiene la propiedad de adherirse a un receptor de la célula uroepitelial, reconociendo un glicolípido formado, principalmente, por globotriacilceramida $y$ globotetraacilceramida, presentes como antigenos de las personas que portan el grupo sanguineo PL. Hay evidencias crecientes de que esta situación aumenta la posibilidad de que una ITU causada por $E$, coli comprometa el riñón ${ }^{5-?}$. A este último mecanismo se le atribuye mayor importancia en la producción del daño renal.

El grupo sanguíneo $P$ fue descubierto en el âto 1927 por Landsteiner y Levine y está cons- 
tituido por tres antígenos glicolipídicos, P1, Py y Pk, de cuya combinación resultan fenotípicamente personas $\mathrm{Pl}$ o $\mathrm{P} 2$, cuya đistribución en nuestra población es $79 \%$ P1 y $21 \% \quad \mathrm{P} 2$. Con los primeros se han establecido relaciones entre ITU y daño renal, por tener mayor densidad de receptores con las características antes mencionadas en las células uroepiteliales, que facilitarian la unión de la $E$. colt a estas célu. las $1,2,4,6$.

Este estudio se realizó con el objeto de veri. ficar la relación entre grupo sanguíneo $P$ y daño renal en nifos con reflujo vesicoureteral con $y$ sin cicatrices renales.

\section{Pacientes y Método}

Se estudiaron treinta nirios, sin considerar edad ni sexo, portadores de rellujo vesicoureteral y nefropatía del reflujo $y$ otros 30 pacientes con reflujo vesicoureteral, pero con indemnidad del parénquima renal, los que fueron considerados como grupo control. Ambos grupos (estudio y control) habían tenido ITU por $E$. colt y fueron controlados en las unidades de nefrología y radiologla del Hospital Luis Calvo Mackenna, de Santiago.

EI reflujo vesicoureteral fue demostrado por uretrocistografía miccional y et estudio renal se realizó con pielografía de eliminación. Se consideraron comprometidos ritiones que tenían una o más de las características siguientes: menor tamaño, disminución del parénquima en alguno de los polos (cicatriz) o deformación de los cálices.

La determinación del grupo sanguíneo P1 se basó en la capacidad de aglutinación de glóbulos rojos que posee este antígeno, midiéndola con un anticuerpo de alta especificidad dirigido contra él. Como reactivo se usó suero anti-P Ortho Diagnostic para grupos sanguíneos. La prueba se realizó con glóbulos rojos abtenidos de ambos grupos de pacientes, lavados y suspendidos en solución isotónica a temperatura ambiente, los cuales fueron mezclados con suero anti-P por cinco minutos, luego centrifugados por quince segundos a 3.400 cpm $y$, finalmente, observados macroscópicamente para presencia o ausencja de aglutinación. La aglutinación indica que existe antigeno P1 y la prueba se considera positiva, clasificándose dichos glóbulos rojos como pertenecientes al grupo sanguíneo P1.

\section{Resultados}

La edad promedio fue 6 años 4 meses para el grupo sin daño renal y 9 años en el otro. En ambos hubo preponderancia del sexo femenino (25 y 23 pacientes, respectivamente).

El grupo sanguíneo $P 1$ se encontró en 20 pacientes $(66,7 \%)$ sin daño renal y en $17(56,7 \%)$ de los que tenían đaryo, no estableciéndose diferencias significativas entre ambos al compararlos estadísticamente por el método chi cuadrado.

\section{Discusión}

A pesar de que las medidas profilácticas pue. den evitar la fornación de cicatrices renales, existe un numero de pacientes que presentan esta complicación de la ITU, sobre todo en la forma recurrente, que está asociada al reflujo vesjcoureteral como factor coadyuvante, situación bastante común en nuestros pacientes ${ }^{1,2}, 14,17,18$. Es por esto que se han buscado marcadores in. directos de la posibilidad de desarrollar cicatrices renales.

La mayoria de estas ITU son producidas por E. $c o l^{15}$, que reconoce receptores en las células uroepiteliales, cuya composición bioquímica es la misma que la de los antigenos del sistema $\mathrm{P}$ de los grupos sanguineos, destacando esa adhesividad como uno de los factores de mayor importancia en su virulencia ${ }^{4,7, *}$, Basados en este hecho, Lomberg? y Fletcher ${ }^{16}$ concluyeron en sus estudios que los pacientes que tienen grupo sanguíneo Pl están expuestos a mayor riesgo de sufrir ITU recurrentes que los pacientes que co. nocen de él.

En nuestra experiencia y en otras, no se demostró correlación entre la portación de grupo sanguíneo Pl y el daño renal, ya que en la mues. tra estudiada la presencia de grupo Pl en ambos niños con reflujo, con y sin cicatrices renales, no se apartó de la frecuencia esperada en la población general y tampoco hubo diferencias significativas entre ellos, no justificándose este examen en el estudio de pacientes con ITU $y$ reflujo vesicoureteral como predictor de eventual daño renal.

\section{Resumen}

En los últimos años se ha insistido en la relación que existiria entre la infección urinaria, la cicatriz. renal $y$ el subgrupo sanguíneo $P$. La infección urinaria, producida la mayoria de las veces por determinados tipos de $\boldsymbol{E}$. coli tendría importancia en el daño renal dado que la $E$. coli tiene capacidad de adherirse al epitelio urinario por medio de fimbrias, reconociendo un receptor de estructura química relacionada, a su 
vez, con el subgrupo $P$. Determinamos el subgrupo $\mathrm{P} 1$ en 30 niños con infección urinaria, reflujo vesicoureteral y sin cicatriz renal, comparándolo con otro grupo de igual cantidad de pacientes portadores de infección urinaria $y$ reflujo, pero con cicatriz renal. El grupo $\mathbf{P 1}$ se encontró presente en $66,7 \%$ de los pacien. tes sin daro renal y en $56,7 \%$ de los que tenían cicatriz renal. Así, pues, no logramos demostrar que el subgrupo P1 sirva como marcador indirecto de riesgo de formacjôn de cicatriz renal, ya que no hubo diferencias entre los dos gru. pos de pacientes estudiados.

(Palabras clave: cicatrices renales, factores de riesgo, grupo sanguineo $P$.)

\section{Referencias}

1. Jodal, $U_{*}$ Winberg, I.: Pyelonephritis (Conference report). Report of the 4th International Symposium. Goteborg, Sweden, 19B6. Pediatr Nephtol $1987 ; 1: 248.252$.

2. Lidefelt, K.J.: Ballgreen, I.; Kallenius, G,; Svenson, $S . B .:$ P fimbriated $E$. coli in children with acute cystitis. Acta Ped Scan 1987; 76: 775-780.

3. Harber, M.J.; Topley, $N_{.:}$Ascher, $A . W_{1}$ : Virulence factor of urinary pathogens. Clin Science 1986 ; $70: 531-538$

4. Lomberg, H.; Hellstrom, M, Jodol, U, Leflet,

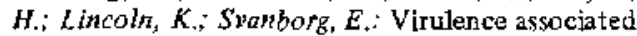
traits in $E$. coli causing first and recurrent episodes of urinary tract infection in children with or without vesico-ureteral reflux. I Infect Dis 1984; $150: 561-569$.

5. Roth, D.R.; Gonzólez, E.T.: Bacterial virulence factors in UTH. Dialogucs in Pediatrics Urology $1986 ; 9,5$.

6. Jacobson, S.H.; Lins, I.E.: Svenson, S.B.; Kallenius, $G$.: Lack of correlation of $\mathrm{P}$ blood group phenotype and renal scarring. Kidney Int 1985 ; $28: 797.799$.

7. Lomberg, $H_{, ;}$Jodal, $U_{n}$; Sunberg, E.: $_{\text {P blood }}$ group and U.T.I. Lancet 1981; 7 : 551-552.

8. Kallenitus, G.: Molby, R.; Syenson, S.B.; Winberg, I.: The $\mathrm{Pk}$ antigen as receptor for the hemagluttinin of pyelonephritis $E$. coli. FEMS Microbiol Lett 1980; 7:297-302.

9. Brooks, S.J.D.: Lyons, J.M.: Brande. A.J.: $\operatorname{lmmu-}$ nization against retrograde pyelonephritis. III. Vaccination against chronic pyelonephritis due to $E$, coli. J Infect Dis 1977; 1 36: 633-639.

10. Svanborg, E.C.: Hanson, L.A.: Jodal, U.; Lintberg, $V$; Aberlund, $A . S$.: Variable adherence to normal human urinary trace epithelial cells of $E$. coli straiss associated with various forms of UTI.

11. Torres, V.E.: Kramer, S.A.i Holley, K.E.: Effect of bacterial immunization on experimental reflux nephropaty. J Urology 1984; 131: 772-776.

12. Chan, R.C.I.; Bruce, $A, W$. Reid, $G$. : Adher ence of cervical, vaginal and distal urethral normal $\mathrm{mi}$ crobial flower to human uroepithelial cells and the inhibition of adherence of gram negative uropathogens by competitive exclution. J Urology 1984;131: 596-600.

13. Svanborg, E.G.: Hansson, H.A.: E. coli as possible mediator of atachment to human urinary trac epithelial cells. Infect Immunol 1978; 21: 229. 237.

14. Dominguez, G.J.; Roberts, J.A.; Lancivica, R.: Pathogenic significance of P-fimbriated $E$. colf in UTJ. J Lirology $1985 ; 133: 983-989$.

15. Kallenits, $G$, Molby, R.; Syenson, S.B.: Ocurrence of P-fimbriated $E$, coli in UTI. Lancet 1981 ; ii: 1360-1372.

16. Fletcher, K.S.; Bruner, E.G.; Schwarting, G.A.: $P$ blood group regulation of glycosphingolipids levels in human erythrocyts. J Biol Chem 1979; 254: $1196-1198$.

17. Winberg, J.; Anderson, H.J.: Bergstrong, T.: Jacobson, B.; Larson, $\boldsymbol{H}$ : Epidemioiogy of syntomatic UTI in childhood. Acta Ped Scand (suppl 1) 1984; 252: $1-20$

18. Woodard, J.R.: Rushton, H.G.' Retlux uropathy. Pediatr Clin N.A. 1987; 34: 1349-1 365. 